\title{
Mortality associated with bone fractures in COPD patients
}

\author{
This article was published in the following Dove Press journal: \\ International Journal of COPD \\ 21 September 2016 \\ Number of times this article has been viewed
}

\author{
Yasuhiro Yamauchi' \\ Hideo Yasunaga ${ }^{2}$ \\ Yukiyo Sakamoto' \\ Wakae Hasegawa' \\ Hideyuki Takeshima' \\ Hirokazu Urushiyama' \\ Taisuke Jol,3 \\ Hiroki Matsui ${ }^{2}$ \\ Kiyohide Fushimi ${ }^{4}$ \\ Takahide Nagase' \\ 'Department of Respiratory Medicine, \\ Graduate School of Medicine, \\ ${ }^{2}$ Department of Clinical Epidemiology \\ and Health Economics, School of \\ Public Health, ${ }^{3}$ Department of Health \\ Services Research, Graduate School \\ of Medicine, The University of Tokyo, \\ ${ }^{4}$ Department of Health Policy and \\ Informatics, Tokyo Medical and \\ Dental University Graduate School of \\ Medicine, Tokyo, Japan
}

Correspondence: Yasuhiro Yamauchi Department of Respiratory Medicine, Graduate School of Medicine, The University of Tokyo, 7-3-I, Hongo, Bunkyo-ku, Tokyo II 3-8655, Japan

$\mathrm{Tel}+8 \mathrm{I} 338 \mathrm{I} 54 \mathrm{II}$

$\mathrm{Fax}+81338155954$

Email yamauchiy-int@h.u-tokyo.ac.jp
Background and objective: COPD is well known to frequently coexist with osteoporosis. Bone fractures often occur and may affect mortality in COPD patients. However, in-hospital mortality related to bone fractures in COPD patients has been poorly studied. This retrospective study investigated in-hospital mortality of COPD patients with bone fractures using a national inpatient database in Japan.

Methods: Data of COPD patients admitted with bone fractures, including hip, vertebra, shoulder, and forearm fractures to 1,165 hospitals in Japan between July 2010 and March 2013, were extracted from the Diagnosis Procedure Combination database. The clinical characteristics and mortalities of the patients were determined. Multivariable logistic regression analysis was also performed to determine the factors associated with in-hospital mortality of COPD patients with hip fractures.

Results: Among 5,975 eligible patients, those with hip fractures $(n=4,059)$ were older, had lower body mass index (BMI), and had poorer general condition than those with vertebral $(n=1,477)$, shoulder $(\mathrm{n}=281)$, or forearm $(\mathrm{n}=158)$ fractures. In-hospital mortality was $7.4 \%, 5.2 \%, 3.9 \%$, and $1.3 \%$, respectively. Among the hip fracture group, surgical treatment was significantly associated with lower mortality (adjusted odds ratio, 0.43 ; 95\% confidence interval, $0.32-0.56$ ) after adjustment for patient backgrounds. Higher in-hospital mortality was associated with male sex, lower BMI, lower level of consciousness, and having several comorbidities, including pneumonia, lung cancer, congestive heart failure, chronic liver disease, and chronic renal failure.

Conclusion: COPD patients with hip fractures had higher mortality than COPD patients with other types of fracture. Surgery for hip fracture was associated with lower mortality than conservative treatment.

Keywords: COPD, hip fractures, in-hospital mortality, surgical treatment

\section{Introduction}

COPD is the third leading cause of death worldwide. ${ }^{1}$ COPD is often accompanied by multiple comorbidities that are associated with systemic inflammation related to COPD and affect mortality in COPD patients. ${ }^{2}$ Osteoporosis is one of the major comorbidities in $\mathrm{COPD}^{3,4}$ and is reported to be associated with poor health status in COPD patients. ${ }^{2}$ Osteoporosis leads to a greater risk of bone fractures, including hip, vertebral, shoulder, and forearm fractures. Hip fracture is the most common type of fracture in elderly patients ${ }^{5}$ and is a well-known risk factor for increased mortality. ${ }^{6-9}$ Previous studies have reported that hip fractures, as well as vertebral and shoulder fractures, were associated with increased mortality in the general population. ${ }^{7-10}$

COPD patients have bone fragility because of osteoporosis and weakness of skeletal muscle related to reduced physical activity. These patients have been encouraged to improve their physical activity, ${ }^{11,12}$ as physical activity has been reported to reduce 
all-cause mortality in COPD patients. ${ }^{13}$ However, physical activities may increase the risk of falls and fall-related injuries. Several studies have also demonstrated an association between mortality and chronic respiratory disease in patients with hip fractures, ${ }^{14-16}$ but previous studies investigating mortality related to hip fractures in COPD patients have been limited because of small sample sizes. ${ }^{17,18}$

To our knowledge, there have been no studies of mortality related to bone fractures, including hip, vertebral, shoulder, and forearm fractures, in COPD patients. This study investigated the clinical characteristics and mortality of COPD patients with bone fractures using a national inpatient database in Japan. In addition, the factors associated with in-hospital mortality of COPD patients with hip fractures were investigated.

\section{Methods}

\section{Database}

The Diagnosis Procedure Combination database, a national inpatient database in Japan, includes administrative claims data and hospital discharge data. ${ }^{19}$ The Diagnosis Procedure Combination database includes data on the following: primary diagnosis on admission; comorbidities present on admission; complications occurring during hospitalization, recorded with the International Classification of Disease and Related Health Problems, 10th Revision (ICD-10) codes accompanied by text data in Japanese; patient discharge status including outcomes; and operative procedures during hospitalization. The database also contains the following information on admission: patient age and sex; body height and weight; level of consciousness based on the Japan Coma Scale; and activities of daily life represented by the Barthel Index.

This study was approved by the Institutional Review Board of the University of Tokyo. The board waived the requirement for patients' informed consent because of the anonymous nature of the data.

\section{Patient selection}

We retrospectively collected data for patients aged 40 years and older who were admitted to hospital with bone fracture as the main diagnosis on admission, had a diagnosis of COPD, and were discharged between July 1, 2010 and March 31, 2013 (Figure 1). Bone fracture on admission was identified

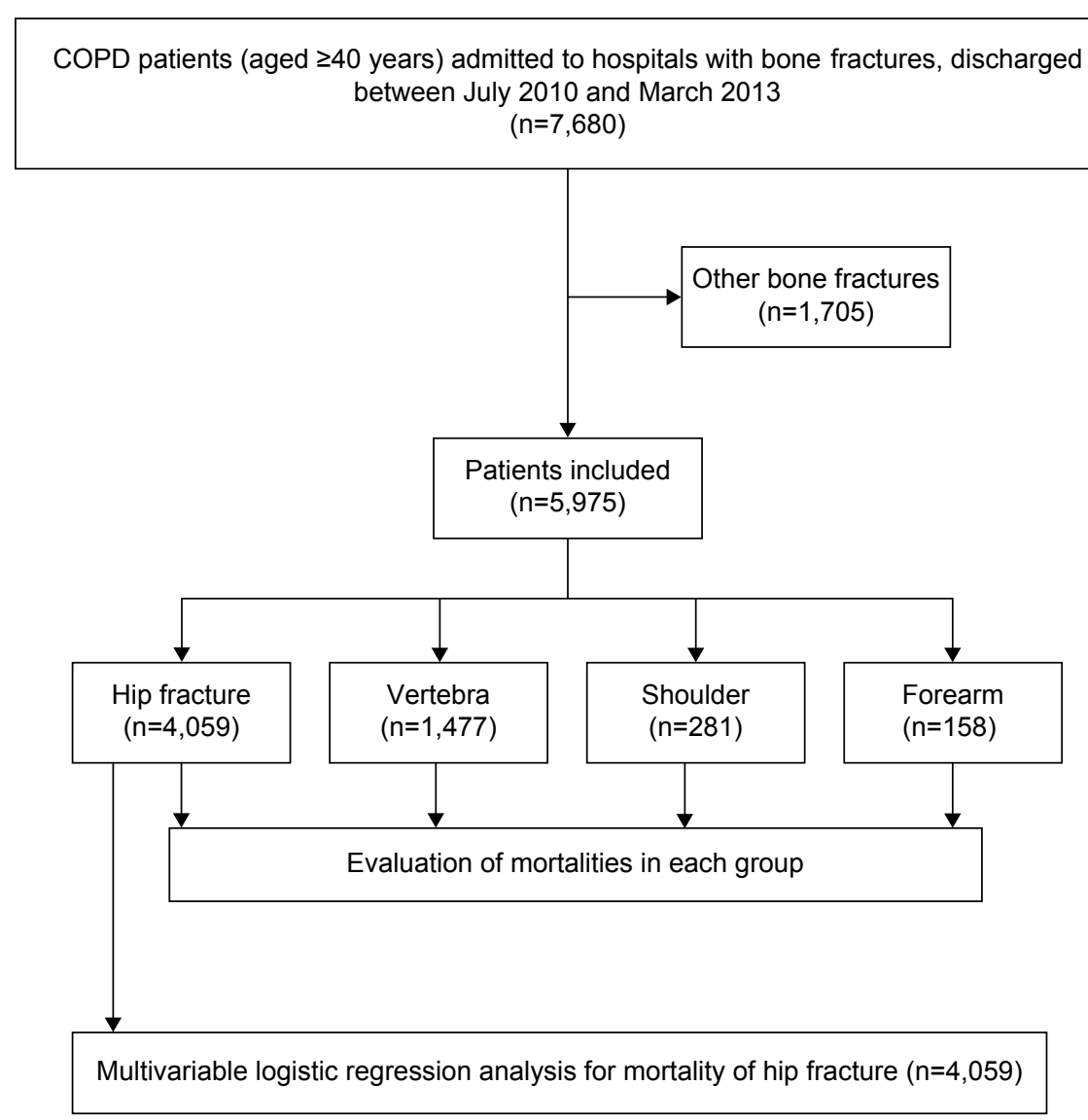

Figure I Flowchart showing the inclusion and exclusion criteria of this study. 
with ICD-10 codes. Hip fracture included fracture of the proximal femur (S720, S721, and S722). Vertebral fracture included fracture of the thoracic and lumbar vertebra (S220, $\mathrm{S} 221$, and S320). Shoulder fracture included fracture of the clavicle, scapula, and proximal humerus (S420, S421, and S422). Forearm fracture included fracture of the distal forearm (S525 and S526). The diagnosis of COPD was based on physician-diagnosed COPD, and having COPD on admission was identified with ICD-10 codes (J41, J42, J43, and J44). Patients who were injured in traffic accidents were excluded (V01x-V99x).

\section{Outcomes}

The primary outcome of this study was all-cause in-hospital mortality.

\section{Statistical analysis}

We used the $\chi^{2}$ test to compare proportions, analyses of variance followed by a post hoc Bonferroni test to compare mean values, and the Kruskal-Wallis test to compare median values between groups. Multivariable logistic regression analysis was used to assess the association between patient-level factors and mortality after adjustment for within-hospital clustering by means of a generalized estimation equation. The threshold for significance was $P<0.05$. Statistical analyses were performed using SPSS Statistics for windows, version 22.0 (IBM Corp., Armonk, NY, USA).

\section{Results \\ Patient characteristics on admission}

A total of 5,975 COPD patients (aged $\geq 40$ years) were admitted to the hospital with bone fractures, 4,059 (67.9\%) with a hip fracture, 1,477 (24.7\%) with a vertebral fracture, $281(4.7 \%)$ with a shoulder fracture, and 158 (2.6\%) with a forearm fracture. Patient characteristics are listed in Table 1. The mean age of the COPD patients with a bone fracture was 81.2 years, and mean body mass index (BMI) was $19.7 \mathrm{~kg} / \mathrm{m}^{2}$. Patients with hip fractures were significantly older (83.2 years), had lower BMI $\left(19.3 \mathrm{~kg} / \mathrm{m}^{2}\right)$, and had poorer general condition than those with other types of fracture. Patients with a forearm fracture were significantly younger, had normal BMI, and were in better condition compared with the other groups.

Comorbidities on admission are listed in Table 2. Major comorbidities in COPD patients with bone fracture were pneumonia, asthma, congestive heart failure, ischemic heart disease, and cerebrovascular disease. The proportions of pneumonia, congestive heart failure, and cerebrovascular disease were higher in the hip fracture group than the other fracture groups.

The clinical course and outcomes are listed in Table 3. Mortality in the hip, vertebral, shoulder, and forearm groups was $7.4 \%, 5.2 \%, 3.9 \%$, and $1.3 \%$, respectively. Length of hospital stay in the hip fracture group was significantly longer than in the other fracture groups. In the hip fracture group,

Table I Clinical characteristics of COPD patients on admission

\begin{tabular}{|c|c|c|c|c|c|c|c|c|c|c|c|}
\hline & Total & & Hip & & Vertebra & & Shoulder & & Forearm & & $P$-value \\
\hline & $n=5,975$ & (\%) & $n=4,059$ & (\%) & $n=I, 477$ & (\%) & $n=28 I$ & (\%) & $n=158$ & (\%) & \\
\hline Age (years) ${ }^{\mathrm{a}}$ & 82.1 (8.2) & & $83.2(7.9)$ & & $80.7(7.5)$ & & $77.4(10.2)$ & & $75.3(9.0)$ & & $<0.001$ \\
\hline 40-79 & $\mathrm{I}, 874$ & $(31.4)$ & 1,069 & $(26.3)$ & 567 & $(38.4)$ & 136 & $(48.4)$ & 102 & $(64.6)$ & \\
\hline$\geq 80$ & 4,101 & $(68.6)$ & 2,990 & (73.7) & 910 & $(61.6)$ & 145 & $(51.6)$ & 56 & (35.4) & \\
\hline Sex & & & & & & & & & & & $<0.001$ \\
\hline Male & 3,122 & (52.3) & 2,087 & (5I.4) & 845 & (57.2) & 150 & (53.4) & 40 & $(25.3)$ & \\
\hline Female & 2,853 & $(47.7)$ & 1,972 & $(48.6)$ & 632 & $(42.8)$ & $|3|$ & $(46.6)$ & 118 & (74.7) & \\
\hline BMI $\left(\mathrm{kg} / \mathrm{m}^{2}\right)^{\mathrm{a}}$ & 19.7 (3.7) & & $19.3(3.6)$ & & $20.2(3.9)$ & & $20.7(3.9)$ & & $22.0(4.3)$ & & $<0.001$ \\
\hline$<18.5$ & 2,198 & $(36.8)$ & 1,609 & (39.6) & 478 & (32.4) & 82 & $(29.2)$ & 29 & $(18.4)$ & \\
\hline $18.5-24.9$ & 2,753 & $(46.1)$ & $I, 8 \mid 4$ & $(44.7)$ & 701 & $(47.5)$ & 145 & $(5 I .6)$ & 93 & $(58.9)$ & \\
\hline$\geq 25.0$ & 440 & $(7.4)$ & 227 & $(5.6)$ & 152 & $(10.3)$ & 31 & $(11.0)$ & 30 & $(19.0)$ & \\
\hline Missing & 584 & (9.8) & 409 & $(10.1)$ & 146 & $(9.9)$ & 23 & $(8.2)$ & 6 & $(3.8)$ & \\
\hline Level of consciousness & & & & & & & & & & & $<0.001$ \\
\hline Clear & 5,410 & $(90.6)$ & 3,601 & (88.7) & 1,392 & $(94.2)$ & 263 & $(93.6)$ & 154 & $(97.5)$ & \\
\hline Drowsy & 533 & $(8.9)$ & 431 & $(10.6)$ & 81 & $(5.5)$ & 17 & $(6.0)$ & 4 & $(2.5)$ & \\
\hline Coma & 31 & $(0.5)$ & 26 & $(0.6)$ & 4 & $(0.3)$ & 1 & $(0.4)$ & 0 & $(0.0)$ & \\
\hline Activities of daily living & & & & & & & & & & & $<0.001$ \\
\hline Independent & $\mathrm{I}, 067$ & $(I 7.9)$ & 406 & $(10.0)$ & 383 & $(25.9)$ & 162 & $(57.7)$ & 116 & $(73.4)$ & \\
\hline Dependent & 3,654 & $(6 \mid .2)$ & 2,762 & $(68.0)$ & 796 & $(53.9)$ & 73 & $(26.0)$ & 23 & $(14.6)$ & \\
\hline Missing & 1,254 & $(21.0)$ & 891 & $(22.0)$ & 298 & $(20.2)$ & 46 & (16.4) & 19 & $(12.0)$ & \\
\hline
\end{tabular}

Notes: a Data expressed as mean (standard deviation). Missing refers to lack of data.

Abbreviation: BMI, body mass index. 
Table 2 Patient comorbidities on admission

\begin{tabular}{|c|c|c|c|c|c|c|c|c|c|c|c|}
\hline & \multicolumn{2}{|l|}{ Total } & \multicolumn{2}{|l|}{ Hip } & \multicolumn{2}{|c|}{ Vertebra } & \multicolumn{2}{|c|}{ Shoulder } & \multicolumn{2}{|c|}{ Forearm } & \multirow[t]{2}{*}{$P$-value } \\
\hline & $n=5,975$ & (\%) & $n=4,059$ & (\%) & $n=1,477$ & (\%) & $\mathbf{n}=\mathbf{2 8}$ I & (\%) & $n=158$ & (\%) & \\
\hline Pneumonia & 500 & $(8.4)$ & 389 & $(9.6)$ & 94 & $(6.4)$ & 14 & $(5.0)$ & 3 & (I.9) & $<0.001$ \\
\hline Asthma & 692 & $(11.6)$ & 437 & $(10.8)$ & 196 & $(13.3)$ & 31 & $(I I .0)$ & 28 & $(17.7)$ & 0.005 \\
\hline Interstitial pneumonia & 97 & $(1.6)$ & 56 & $(1.4)$ & 38 & $(2.6)$ & 3 & $(I .1)$ & 0 & $(0.0)$ & 0.005 \\
\hline Lung cancer & 184 & $(3.1)$ & 108 & $(2.7)$ & 65 & $(4.4)$ & 9 & $(3.2)$ & 2 & $(1.3)$ & 0.005 \\
\hline Congestive heart failure & 674 & $(11.3)$ & 496 & $(12.2)$ & $|5|$ & $(10.2)$ & 19 & $(6.8)$ & 8 & $(5.1)$ & 0.001 \\
\hline Ischemic heart disease & 605 & $(10.1)$ & 411 & $(10.1)$ & 143 & $(9.7)^{\prime}$ & 27 & (9.6) & 24 & $(15.2)$ & 0.183 \\
\hline Arrhythmia & 302 & $(5.1)$ & 223 & $(5.5)$ & 62 & $(4.2)$ & 10 & (3.6) & 7 & $(4.4)$ & 0.149 \\
\hline Cerebrovascular disease & 569 & (9.5) & 419 & $(10.3)$ & 120 & (8.1) & 20 & (7.1) & 10 & (6.3) & 0.018 \\
\hline Chronic liver disease & 88 & $(1.5)$ & 61 & $(1.5)$ & 24 & $(1.6)$ & 0 & $(0.0)$ & 3 & (1.9) & 0.199 \\
\hline Chronic renal failure & 149 & (2.5) & 115 & (2.8) & 28 & (1.9) & 5 & (1.8) & I & $(0.6)$ & 0.074 \\
\hline
\end{tabular}

3,220 (79.3\%) patients received surgical treatment. Mortality in the surgically treated hip fracture group was $5.3 \%$, while that in the conservatively treated hip fracture group was $15.4 \%$.

The results of the multivariable logistic regression analysis of factors associated with mortality in COPD patients with hip fractures are listed in Table 4. Higher mortality was associated with male sex, lower BMI, and lower level of consciousness on admission. Surgical treatment of hip fracture was associated with lower mortality compared with conservative treatment (adjusted odds ratio, 0.43; 95\% confidence interval, $0.32-0.56 ; P<0.001)$. Comorbidities of pneumonia, interstitial pneumonia, lung cancer, congestive heart failure, chronic liver disease, and chronic renal failure were also associated with higher mortality in COPD patients with hip fracture.

\section{Discussion}

This retrospective study, using data from a national inpatients database in Japan, established that COPD patients with hip fractures had higher in-hospital mortality than COPD patients with other types of bone fractures. Hip fracture patients were also older and had lower BMI than patients with other types of fracture. In the hip fracture group, patients who underwent surgical treatment had significantly lower mortality than those who received conservative treatment. Higher mortality was associated with male sex, lower BMI, lower level of consciousness on admission, and several comorbidities.

Previous studies have shown that hip fractures were associated with increased mortality in elderly patients; ${ }^{5-8}$ COPD was also reported to be associated with increased mortality in patients with hip fracture. ${ }^{14-17}$ Thus, mortality associated with hip fractures in COPD patients was expected to be high, and this was confirmed in this study. In-hospital mortality of COPD patients with a vertebral fracture was also higher than in patients with shoulder or forearm fractures. Vertebral fractures have also been reported to be associated with increased mortality in the general population. ${ }^{9}$ A previous study demonstrated that long-term mortality in spine fracture patients was as high as that of patients with hip fractures. ${ }^{10}$ Another recent study reported that vertebral fractures in COPD patients were associated with an increase in long-term mortality. ${ }^{20}$ These findings suggest that COPD patients should take care to prevent osteoporotic fractures, particularly hip and vertebral fractures.

Our study demonstrated that the prevalence of hip fracture was more frequent in male COPD patients than female COPD patients. However, hip fracture is well known to be

Table 3 Clinical course and outcomes

\begin{tabular}{|c|c|c|c|c|c|c|c|c|c|c|c|}
\hline & \multicolumn{2}{|l|}{ Total } & \multicolumn{2}{|l|}{ Hip } & \multicolumn{2}{|l|}{ Vertebra } & \multicolumn{2}{|c|}{ Shoulder } & \multicolumn{2}{|c|}{ Forearm } & \multirow[t]{2}{*}{$P$-value } \\
\hline & $n=5,975$ & (\%) & $n=4,059$ & (\%) & $n=1,477$ & (\%) & $\mathbf{n}=\mathbf{2 8} I$ & (\%) & $n=158$ & (\%) & \\
\hline Death & 389 & $(6.5)$ & 299 & $(7.4)$ & 77 & $(5.2)$ & 11 & (3.9) & 2 & $(1.3)$ & $<0.001$ \\
\hline Length of stay, days ${ }^{a}$ & \multicolumn{2}{|l|}{$31(20-50)$} & \multicolumn{2}{|l|}{$34(22-53)$} & \multicolumn{2}{|l|}{$29(19-47)$} & \multicolumn{2}{|c|}{$23(12-36)$} & \multicolumn{2}{|c|}{$12(5-12)$} & $<0.001$ \\
\hline With surgery & 3,476 & $(58.2)$ & 3,220 & (79.3) & 63 & $(4.3)$ & 165 & (58.7) & 88 & $(55.7)$ & $<0.001$ \\
\hline Death $^{\mathrm{b}}$ & 177 & $(5.1)$ & 170 & $(5.3)$ & 3 & $(4.8)$ & 4 & $(2.4)$ & 0 & $(0.0)$ & 0.055 \\
\hline Without surgery & 2,499 & $(4 I .8)$ & 839 & $(20.7)$ & $\mathrm{I}, 474$ & $(95.7)$ & 116 & $(4 \mid .3)$ & 70 & $(44.3)$ & \\
\hline Death $^{c}$ & 212 & (8.6) & 129 & (I5.4) & 74 & (5.2) & 7 & $(6.1)$ & 2 & (2.9) & $<0.001$ \\
\hline
\end{tabular}

Notes: a Median (interquartile range); ${ }^{b}$ percentage among patients with surgery; ' percentage among patients without surgery. 
Table 4 Multivariable logistic regression analysis of COPD patients with hip fractures $(n=4,059)$

\begin{tabular}{|c|c|c|c|}
\hline & aOR & $95 \% \mathrm{Cl}$ & $P$-value \\
\hline \multicolumn{4}{|l|}{ Age (years) } \\
\hline 40-79 & Ref & & \\
\hline$\geq 80$ & 1.21 & $0.89-1.66$ & 0.229 \\
\hline \multicolumn{4}{|l|}{ Sex } \\
\hline Male & Ref & & \\
\hline Female & 0.42 & $0.32-0.56$ & $<0.001$ \\
\hline \multicolumn{4}{|l|}{ BMI $\left(\mathrm{kg} / \mathrm{m}^{2}\right)$} \\
\hline$<18.5$ & 2.10 & $1.58-2.79$ & $<0.001$ \\
\hline $18.5-24.9$ & Ref & & \\
\hline$\geq 25.0$ & 0.63 & $0.27-1.45$ & 0.276 \\
\hline Missing & 2.47 & $1.64-3.70$ & $<0.00 \mathrm{I}$ \\
\hline \multicolumn{4}{|l|}{ Level of consciousness } \\
\hline Clear & Ref & & \\
\hline Drowsy & 1.36 & $0.91-2.03$ & 0.137 \\
\hline Coma & 3.70 & $1.36-10.07$ & 0.010 \\
\hline \multicolumn{4}{|l|}{ Activity of daily living } \\
\hline Independent & Ref & & \\
\hline Dependent & 1.12 & $0.7 I-I .78$ & 0.954 \\
\hline Missing & 0.94 & $0.55-1.58$ & 0.805 \\
\hline \multicolumn{4}{|l|}{ Surgery with anesthesia } \\
\hline Yes & 0.43 & $0.32-0.56$ & $<0.001$ \\
\hline \multicolumn{4}{|l|}{ Comorbidities } \\
\hline Pneumonia & 4.65 & $3.47-6.23$ & $<0.001$ \\
\hline Asthma & 1.04 & $0.64-1.68$ & 0.713 \\
\hline Interstitial pneumonia & 4.47 & $2.12-9.41$ & $<0.00 \mathrm{I}$ \\
\hline Lung cancer & 2.47 & $1.33-4.59$ & 0.004 \\
\hline Congestive heart failure & 1.95 & $1.40-2.72$ & $<0.001$ \\
\hline Ischemic heart disease & 1.41 & $0.95-2.09$ & 0.090 \\
\hline Arrhythmia & 1.45 & $0.89-2.38$ & 0.140 \\
\hline Cerebrovascular disease & 0.84 & $0.52-1.36$ & 0.480 \\
\hline Chronic liver disease & 2.60 & I. $17-5.77$ & 0.019 \\
\hline Chronic renal failure & 1.88 & $1.00-3.53$ & 0.050 \\
\hline
\end{tabular}

Note: Missing refers to lack of data.

Abbreviations: aOR, adjusted odds ratio; $\mathrm{Cl}$, confidence interval; Ref, reference; BMI, body mass index.

more frequent in females than males in general population. ${ }^{5,21}$ This discrepancy might be explained based on the frequency of male COPD patients and the existence of osteoporosis as one of the comorbidities of COPD. Our previous study demonstrated that males were four times more likely to suffer from COPD than females. ${ }^{22}$ Furthermore, COPD frequently coexists with osteoporosis, which leads to bone fracture. Thus, hip fracture in male COPD patients might be more frequent than in female COPD patients.

This study demonstrated that mortality of hip fracture patients who underwent surgery was $5.3 \%$. A previous study demonstrated that short-term mortality of surgically treated hip fracture patients in general populations was around $1 \%-2 \%,{ }^{23}$ whereas that in COPD patients was reported to be around $12 \%,{ }^{18}$ this indicates that surgical treatment for hip fracture in patients with COPD had more perioperative complications and higher mortality. ${ }^{18}$ The mortality in this study was higher than that reported in the general population, and compatible with previous findings. ${ }^{18}$

This study also demonstrated that mortality in COPD patients with hip fractures who underwent surgery was significantly lower than that of patients who underwent conservative treatment (15.4\%), after adjustment for patient backgrounds. A previous report demonstrated that urgent scheduling of hip fracture surgery in COPD patients was associated with lower mortality, ${ }^{18}$ and it was confirmed by this study. To the best of our knowledge, there are no previous reports regarding mortality in conservatively treated hip fractures in COPD patients. However, this study indicates that surgical treatment should be recommended for COPD patients with hip fractures, rather than conservative treatment.

Mortality in COPD patients with hip fractures was also found to be associated with several comorbidities, including pneumonia, interstitial pneumonia, lung cancer, congestive heart failure, and chronic liver disease. Previous studies demonstrated that congestive heart failure and poor renal function were associated with higher mortality in patients with hip fractures, ${ }^{16,18}$ and these findings were consistent with this study. Therefore, treatments for comorbid diseases may be crucial for the management of COPD patients to reduce the risk of bone fractures in such patients.

\section{Limitations}

There are several limitations in this study. First, our database does not contain parameters of pulmonary function tests, which could evaluate airflow limitation and indicate the severity of COPD. Therefore, we could not evaluate the association between mortality and severity of COPD. Second, the database does not contain information related to osteoporosis, such as bone mineral density and treatment. Therefore, we could not investigate the association between mortality and osteoporosis in COPD.

\section{Conclusion}

In conclusion, mortality was highest in COPD patients with hip fractures, followed by those with vertebral fractures. Surgically treated hip fractures were associated with lower mortality in COPD patients, compared with conservative treatment. Pneumonia and congestive heart failure were also associated with higher mortality in COPD patients with hip fracture. The study indicates that COPD patients should take care to prevent bone fractures, especially hip and vertebral fractures; nevertheless, such patients are generally encouraged to maintain or increase physical activities to improve their prognosis. 


\section{Acknowledgments}

This work was supported in part by grants-in-aid for scientific research from the Ministry of Education, Science, Sports, Culture and Technology of Japan (YY, 15K09211; TN, 16H02653), Grant to the Respiratory Failure Research Group, and Grants for Research on Policy Planning and Evaluation from the Ministry of Health, Labor, and Welfare, Japan (grant numbers: H28-Policy-Designated-009 and H27-Policy- Strategy-011).

\section{Disclosure}

The authors report no conflicts of interest in this work.

\section{References}

1. World Health Organization. The top 10 causes of death; 2013. Available from: http://www.who.int/mediacentre/factsheets/fs310/en/. Accessed 14 March 2014.

2. Vestbo J, Hurd SS, Agusti AG, et al. Global strategy for the diagnosis, management, and prevention of chronic obstructive pulmonary disease: GOLD executive summary. Am J Respir Crit Care Med. 2013;187: 347-365.

3. Fabbri LM, Luppi F, Beghe B, Rabe KF. Complex chronic comorbidities of COPD. Eur Respir J. 2008;31:204-212.

4. Ferguson GT, Calverley PM, Anderson JA, et al. Prevalence and progression of osteoporosis in patients with COPD: results from the towards a revolution in COPD health study. Chest. 2009;136:1456-1465.

5. Cooper C, Campion G, Melton LJ 3rd. Hip fractures in the elderly: a world-wide projection. Osteoporos Int 1992;2:285-289.

6. Farahmand BY, Michaelsson K, Ahlbom A, Ljunghall S, Baron JA, Swedish Hip Fracture Study G. Survival after hip fracture. Osteoporos Int. 2005;16:1583-1590.

7. Cooper C, Atkinson EJ, Jacobsen SJ, O'Fallon WM, Melton LJ 3rd. Population-based study of survival after osteoporotic fractures. $\mathrm{Am} \mathrm{J}$ Epidemiol. 1993;137:1001-1005

8. Cauley JA, Thompson DE, Ensrud KC, Scott JC, Black D. Risk of mortality following clinical fractures. Osteoporos Int. 2000;11:556-561.
9. Center JR, Nguyen TV, Schneider D, Sambrook PN, Eisman JA. Mortality after all major types of osteoporotic fracture in men and women: an observational study. Lancet. 1999;353:878-882.

10. Johnell O, Kanis JA, Oden A, et al. Mortality after osteoporotic fractures. Osteoporos Int. 2004;15:38-42.

11. Troosters T, van der Molen T, Polkey M, et al. Improving physical activity in COPD: towards a new paradigm. Respir Res. 2013;14:115.

12. Vaes AW, Garcia-Aymerich J, Marott JL, et al. Changes in physical activity and all-cause mortality in COPD. Eur Respir J. 2014;44:1199-1209.

13. Waschki B, Kirsten A, Holz O, et al. Physical activity is the strongest predictor of all-cause mortality in patients with COPD: a prospective cohort study. Chest. 2011;140:331-342.

14. Nettleman MD, Alsip J, Schrader M, Schulte M. Predictors of mortality after acute hip fracture. J Gen Intern Med. 1996;11:765-767.

15. Roche JJ, Wenn RT, Sahota O, Moran CG. Effect of comorbidities and postoperative complications on mortality after hip fracture in elderly people: prospective observational cohort study. BMJ. 2005;331:1374.

16. Radcliff TA, Henderson WG, Stoner TJ, Khuri SF, Dohm M, Hutt E. Patient risk factors, operative care, and outcomes among older communitydwelling male veterans with hip fracture. J Bone Joint Surg Am. 2008; 90:34-42.

17. de Luise C, Brimacombe M, Pedersen L, Sorensen HT. Chronic obstructive pulmonary disease and mortality following hip fracture: a population-based cohort study. Eur J Epidemiol. 2008;23:115-122.

18. Regan EA, Radcliff TA, Henderson WG, et al. Improving hip fractures outcomes for COPD patients. COPD. 2013;10:11-19.

19. Yasunaga H, Matsui H, Horiguchi H, Fushimi K, Muatsuda S. Health services research using the diagnosis procedure combination database in Japan. Asian Pac J Dis Manag. 2013;7:19-24.

20. Kim GW, Joo HJ, Park TS, et al. Vertebral compression fractures may increase mortality in male patients with chronic obstructive pulmonary disease. Int J Tuberc Lung Dis. 2015;19:603-609.

21. Orimo H, Yaegashi Y, Onoda T, Fukushima Y, Hosoi T, Sakata K. Hip fracture incidence in Japan: estimates of new patients in 2007 and 20-year trends. Arch Osteopros. 2009;4:71-77.

22. Hasegawa W, Yamauchi Y, Yasunaga H, et al. Factors affecting mortality following emergency admission for chronic obstructive pulmonary disease. BMC Pulm Med. 2014;14:151.

23. McGinn T, Conte JG, Jarrett MP, El Sayegh D. Decreasing mortality for patients undergoing hip fracture repair surgery. Jt Comm J Qual Patient Saf. 2005;31:304-307.
International Journal of COPD

\section{Publish your work in this journal}

The International Journal of COPD is an international, peer-reviewed journal of therapeutics and pharmacology focusing on concise rapid reporting of clinical studies and reviews in COPD. Special focus is given to the pathophysiological processes underlying the disease, intervention programs, patient focused education, and self management protocols.

\section{Dovepress}

This journal is indexed on PubMed Central, MedLine and CAS. The manuscript management system is completely online and includes a very quick and fair peer-review system, which is all easy to use. Visit http://www.dovepress.com/testimonials.php to read real quotes from published authors. 